\title{
Proposta de Ações Ergonômicas para Mitigar Perdas com Absenteísmo e Presenteísmo
}

RODRIGUES Maíra Marques

Fisioterapeuta do Trabalhador e do trabalho/Ergonomista

\section{Informações do Artigo}

Histórico:

Recebimento: Julho 2017

Revisão: Julho 2017

Aprovação: Setembro 2018

Palavras-chave:

Ergonomia

Absenteísmo

Presenteísmo
Resumo:

Este estudo visa contribuir para a diminuição dos índices de afastamento do trabalho e dapresença não produtiva, aumentando assim as horas efetivamente trabalhadas e consequentemente a produtividade. Nesta perspectiva, a consolidação deste estudo é estratégica para a corporação na medida em que fortalece valores institucionais e fornece constante estímulo à melhoria contínua, pois atua como dispositivo para revisar aspectos da cultura organizacional, promovendo discussão sobre a etiologia do adoecimento no trabalho, instigando à revisão de falsas crenças e a análise dos processos de trabalho, além de apresentar resultados que são demonstrados nas instâncias financeiras e de satisfação e valorização dos trabalhadores.

\section{Introdução}

Este estudo visa contribuir para a diminuição dos índices de afastamento do trabalho e da presença não produtiva, aumentando assim as horas efetivamente trabalhadas e consequentemente a produtividade. Nesta perspectiva, a consolidação deste estudo é estratégica para a corporação na medida em que fortalece valores institucionais e fornece constante estímulo à melhoria contínua, pois atua como dispositivo para revisar aspectos da cultura organizacional, promovendo discussão sobre a etiologia do adoecimento no trabalho, instigando à revisão de falsas crenças e a análise dos processos de trabalho, além de apresentar resultados que são demonstrados nas instâncias financeiras e de satisfação e valorização dos trabalhadores.
Verifica-se, diante do contexto abordado no tema da pesquisa, a oportunidade de apresentar uma ferramenta de gestão capaz de contribuir para aspectos importantes da organização. Muitas empresas utilizam os indicadores de absenteísmo para analisar os resultados da ação ergonômica, porém sem entender claramente essa relação. Além disso, esses indicadores não apontam precisamente como interferir nessa realidade gerando benefícios. Isso sugere que a solução que porventura possa ser encontrada, tem a possibilidade de ser aproveitada por empresas, sejam do mesmo segmento ou mesmo de outros segmentos, e talvez possam ser replicadas na prática.

A pesquisa foi aplicada em um grupo formado por três empresas de um grupo, que atuam nos segmentos de pesquisa mineral, sondagem e produção de bentonita em operação em diversos 
estados do país, entre os anos de 2014 a 2016. Os dados, colhidos dos setores de Recursos Humanos, Saúde e Segurança do Trabalho e Programação da Produção referiam-se tanto as áreas administrativas quanto operacional. Foram colhidos ainda dados referentes a todas as unidades da empresa através da análise da Análise Ergonômica do Trabalho realizada previamente.

\section{Algumas Definições}

Ergonomia (ou Fatores Humanos), segundo a Associação Internacional de Ergonomia - IEA (2000), é uma disciplina científica relacionada ao entendimento das interações entre os seres humanos e outros elementos ou sistemas, à aplicação de teorias, princípios, dados e métodos a projetos a fim de otimizar o bem estar humano e o desempenho global do sistema. Os ergonomistas contribuem para o planejamento, projeto e a avaliação de tarefas, postos de trabalho, produtos, ambientes e sistemas de modo a torná-los compatíveis com as necessidades, habilidades e limitações das pessoas.

O Absenteísmo, também conhecido como absentismo e ausentismo, é conceituado de diversas formas de acordo com a concepção de diferentes autores.

Em Chiavenato (1994), o absenteísmo é considerado a falta ou a ausência de um empregado em seu ambiente de trabalho e pode ser definido também como incapacidade temporária ou permanente dessa ausência. Já de acordo com Gehring Junior et al. (2007) o termo absenteísmo, significa a falta de assiduidade ao trabalho ou a outras obrigações sociais. Isso geralmente significa que o trabalho é feito de forma menos eficiente por outro empregado ou não é feito. Em relação à organização do trabalho, o absenteísmo tem se traduzido em insatisfação, desmotivação e sobrecarga da equipe de trabalho e pode ser indicativo da existência de problemas extremamente preocupantes quando ocasionado por doença (SILVA; MARZIALE, 2000). Apresenta-se a seguir as cinco categorias do absenteísmo (INOUE et.al., 2008):

1. Absenteísmo-doença: ausência justificada por licença saúde;

2. Absenteísmo por patologia profissional: causado por acidente de trabalho e/ou doença profissional;

3. Absenteísmo legal: respaldado por lei;

4. Absenteísmo-compulsório: por suspensão imposta pelo patrão, por prisão ou por outro impedimento de comparecer ao trabalho;

5. Absenteísmo voluntário: por razões particulares não justificadas.

Páez e Abellán, (2015), o conceito de Presenteísmo veio evoluindo consideravelmente nos últimos anos. Segundo os autores, a literatura apresenta duas vertentes quanto ao presenteísmo. Por um lado, a definição econômica: redução da produtividade no trabalho devido a problemas de saúde. Por outro lado, a definição social e comportamental que indica que o presenteísmo corresponde a trabalhar apesar de apresentar um problema de saúde.

Segundo Penha (2010), os fatores prováveis que favorecem o presenteísmo são: clima organizacional ruim, a falta de motivação para o trabalho e problemas de saúde (físicos ou psicológicos), insatisfação, pessimismo, desânimo, alto nível de estresse. Isto traz consequências para a empresa e também a uma parcela dos colegas de trabalho que, muitas vezes são contaminados por esta apatia, falta de produtividade e tomada de ação. Estes fatores geram impactos diretos na qualidade de vida do trabalhador. Caso o empregador não apresente nenhum programa visando à redução do presenteísmo, várias patologias podem ser desencadeadas em função da má da qualidade de vida no trabalho.

De acordo com Penha (2010), a identificação do trabalhador absenteísta na maioria das vezes não é difícil, há apresentação de documentos que justifiquem a ausência ao trabalho. Ao contrário,o presenteísmo nem sempre é aparente, há necessidade de um 
acompanhamento mais próximo para medir prejuízos para o empregado e para os colegas de trabalho, haja vista que o presenteísmo é considerado um inimigo oculto da produtividade. Para o autor, o mais importante e difícil de medir é o presenteísmo, chega a causar passivos oito vezes maiores que os por absenteísmo, sendo indicador muito mais precoce de acúmulo de passivos, quando chega a afastar, o retorno fica mais difícil.

\section{Estudo de Caso}

O estudo de caso se trata de um grupo formado por três empresas, que atuam nos segmentos de pesquisa mineral, sondagem de solo e produção de bentonita. Atualmente possui cerca de 1320 empregados divididos em obras em diversas localidades. Hoje o elevado índice de absenteísmo no trabalho está significativamente relacionado aos problemas ergonômicos que são vivenciados no dia a dia das empresas. Desta forma, o método de pesquisa permite investigar fenômenos organizacionais, dentre eles os processos organizacionais, mantendo-se as suas características dentro do seu contexto (YIN, 2005). Foram formuladas relações de confronto para os dados colhidos nos setores diversos. A Análise Ergonômica do Trabalho (AET), realizada entre 2012 e 2014, apresenta gráficos que ilustram a pesquisa feita com todos os trabalhadores da empresa e entre eles alguns detinham informações importantes a cerca da saúde da percepção de saúde dos trabalhadores e quanto ao absenteísmo:

Gráfico 1 - Satisfação com a qualidade de vida no trabalho

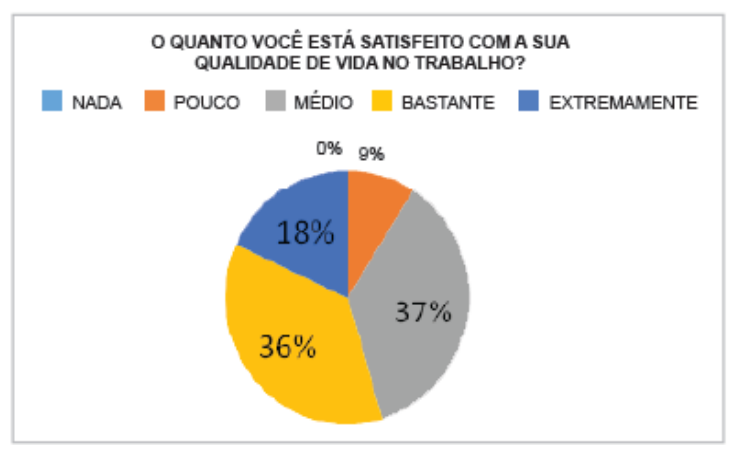

Fonte: AET
Gráfico 2 - Percepção sobre assiduidade no trabalho

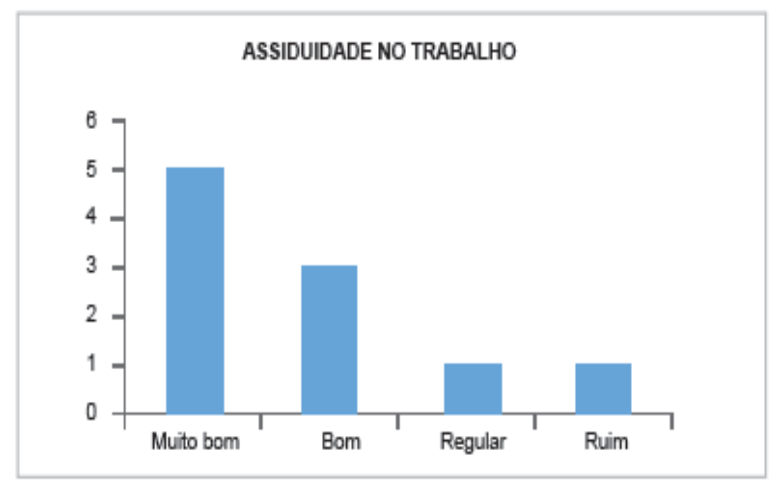

Fonte: AET

Gráfico 3 - Percepção da relação dos sintomas com o trabalho realizado

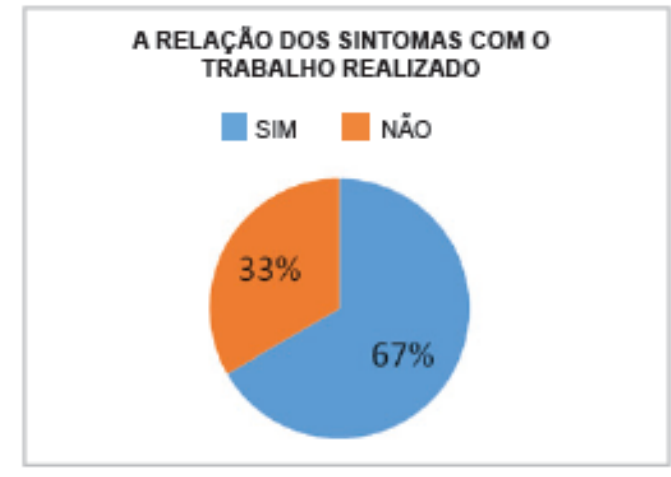

Fonte: AET

Gráfico 4 - Percentual de trabalhadores que já apresentaram problemas de saúde enquanto trabalhavam

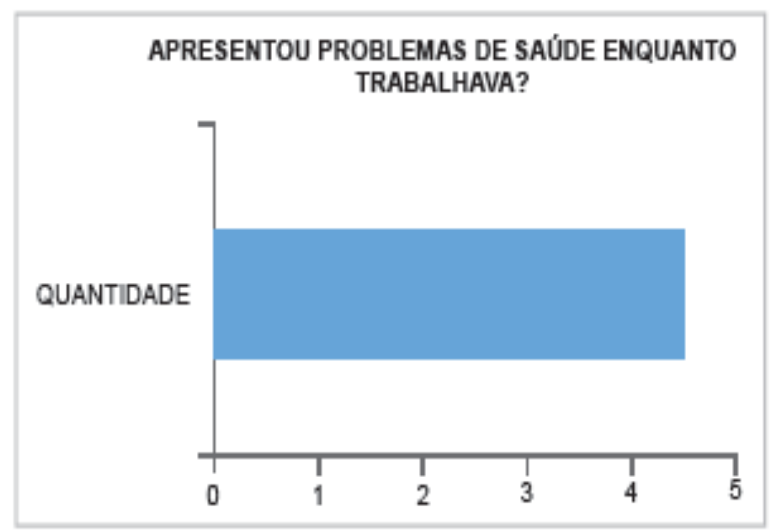

Fonte: AET 
Gráfico 5 - Percentual de trabalhadores que necessitaram de afastamento devido a problemas de saúde

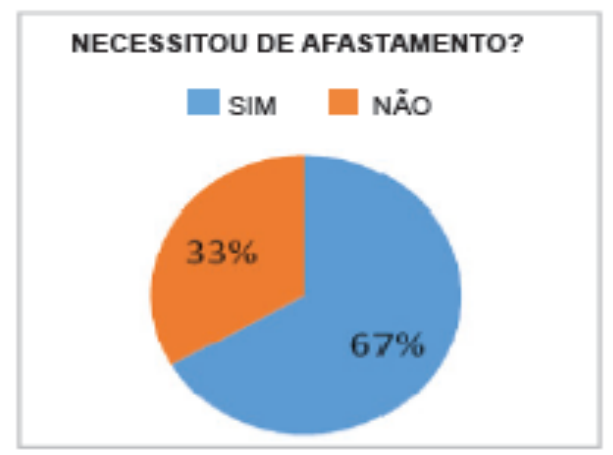

Fonte: AET

Gráfico 6 - Percentual dos trabalhadores que necessitaram de afastamento (volume do afastamento em dias)

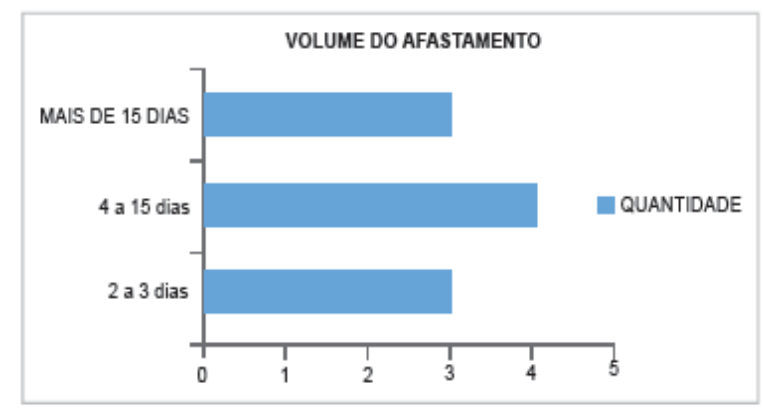

Fonte: AET

Os gráficos apresentados na AET da empresa estudada mostram informações curiosas. A maioria dos trabalhadores diz estar de médio a bastante satisfeito com a qualidade de vida no trabalho, assim como mostra o Gráfico 1 . E como indica o Gráfico 2, quase $50 \%$ consideram sua assiduidade no trabalho como "muito boa". No entanto $67 \%$ relacionaram os sintomas que possuíam com o trabalho (Gráfico 3), 44\% relatam já ter tido problemas de saúde enquanto trabalhavam (Gráfico 4), e $67 \%$ que necessitaram de afastamento (Gráfico 5). Como se trata da percepção do trabalhador e não há confirmação com a relação direta entre os relatos e o real afastamento, é possível em que haja casos que esse afastamento não tenha ocorrido apesar de que o próprio trabalhador o julgasse necessário naquele momento.

O Gráfico 6 demonstra o montante de trabalhadores que necessitaram de afastamento e a quantidade em dias do absenteísmo. É importante ressaltar que apesar de ilustrar dados de tempo de absenteísmo preocupante, o gráfico não considera a reincidência.

Esses dados revelam que a repercussão do presenteísmo pode estar mais presente do que se supunha. Os trabalhadores se julgam assíduos, todavia confirmam que relacionam os sintomas com o trabalho e que já haviam tido problemas de saúde relacionado. A questão a ser debatida é: não há registros de visitas ao setor médico da empresa desse montante de trabalhadores que fizeram esse relato. Há fortes indícios que permaneceram no trabalho, sem ao menos procurar o serviço médico, apesar do adoecimento.

Apesar dos achados dos gráficos, nos resultados da AET não foram apresentados dados relativos ao presenteísmo, tampouco o setor de recursos humanos é detentor destes dados. Não há na empresa indicadores relativos ao presenteísmo.

A Figura 1 retrata o absenteísmo na empresa estudada. Sem apontar os volumes, a árvore do absenteísmo ilustra as causas dos afastamentos e esclarece bem alguns pontos importantes. Além das causas esperadas e mais comuns aparecem de forma importante as causas de absenteísmo por "doenças" (não diagnosticadas) e o voluntário.

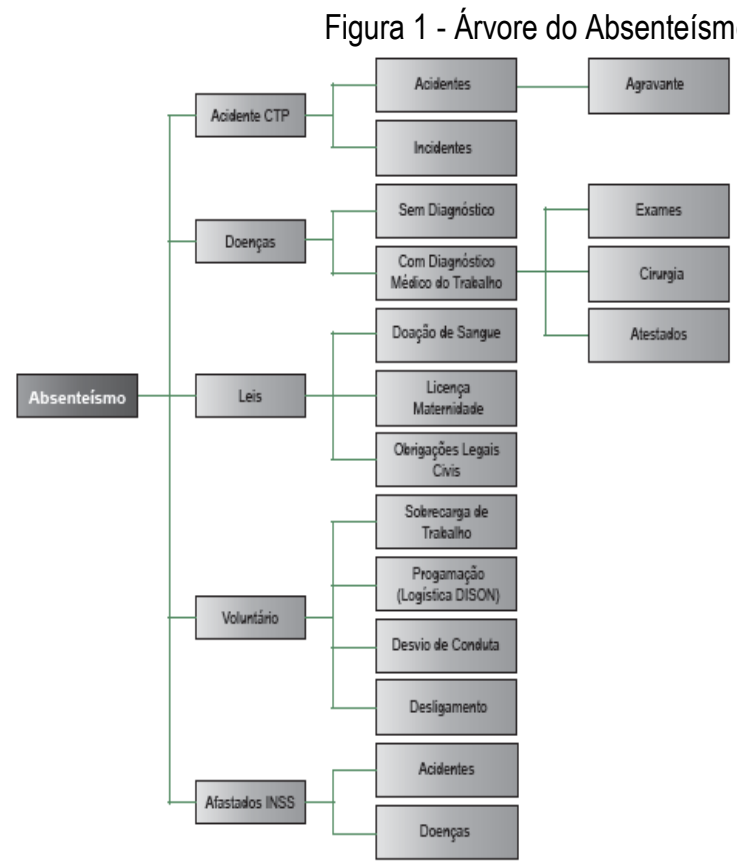

Fonte: Autora (2016)

DISON: Divisão de Sondagem (programação operacional); CTP: com tempo perdido 
Evidenciou-se através da análise de dados dos setores de programação operacional que há uma autonomia implícita de gestores sobre folgas e controle de fluxo de pessoal na produção que foge do controle atual dos setores de recursos humanos e medicina do trabalho, mas que certamente impactam e mascaram os índices de absenteísmo. Essa autonomia em permitir e abonar faltas é benéfica sob a ótica das relações de trabalho e gestão de fadiga, porém pode corroborar para o descontrole dos níveis de absenteísmo e gestão de suas consequências.

Avaliando os indicadores de rotatividades pode-se perceber que havia casos de trabalhadores que abandonavam o emprego, muitas vezes não retornando após sua folga (com frequência moradores de outros estados e recém-contratados) que por falta de comunicação permanecem na lista de trabalhadores afastados até que seja comprovado legalmente o abandono de emprego (na árvore do absenteísmo com desligamento). Essa dificuldade na contratação eficaz, monitoramento e controle do contingente estimula a elevação e permanência em índices altos de absenteísmo.

Propõe-se um modelo de gestão do absenteísmo e presenteísmo através da metodologia Ergonômica (com base na análise ergonômica do trabalho) e baseado em fundamentos epidemiológicos e se destina a traçar um panorama do local de trabalho, indicando a presença de doenças e fatores de risco que podem influenciar no absenteísmo, no presenteísmo e nos custos (de produção ou assistenciais).

\section{As Ações Ergonômicas foram Divididas em Duas Etapas:}

\section{1) Identificação do absenteísmo/ presenteísmo:}

Assim como exposto no Quadro 1 (no Anexo A), Calil et al. (2015), afirmam que o mapeamento adequado do absenteísmo/presenteísmo e suas causas permitem refletir sobre as condições laborais e a elaboração de políticas e estratégias de gestão de pessoas.
É importante lembrar que segundo Inoue et al. (2008) para que as empresas consigam identificar o real motivo das ausências dos seus empregados, faz- se necessário um estudo mais detalhado das causas e consequências do absenteísmo. Além disso, de acordo com Martiniano (2012), as empresas que direcionam medidas excessivas à redução do absenteísmo, ocasionam um aumento de presenteísmo, que em longo prazo podem aumentar o afastamento por doenças (absenteísmo prolongado).

De acordo com Martinez et al. (2007), há um instrumento que permite a avaliação do presenteísmo, Stanford Presenteísmo Scale-6 (SPS-6) demonstrado como uma das medidas de investigação na etapa 1 do Quadro 1 (no Anexo A). A escala do SPS-6 é constituída por seis afirmações baseadas numa escala do tipo Likert com cinco níveis de resposta (de 1 - discordo totalmente a 5 - concordo totalmente). Esta é uma das mais interessantes medidas disponíveis para estimar as perdas de produtividade laboral e tem sido um dos instrumentos mais utilizados para medir o presenteísmo.

Outro contribuinte importante para o aprofundamento das informações sobre absenteísmo/ presenteísmo é o uso das Ferramentas de Análise Ergonômicas. Reitera-se a colocação de Vilela et al. (2011) que diz que a ergonomia da atividade contribuiu para compreender as causas organizacionais ultrapassando os aspectos normativos da vigilância tradicional, o que indica sua importância para tornar mais efetivas as ações de vigilância para a prevenção.

Como citado nas etapas 01 e 02 do Quadro 11 (no Anexo A), através do programa de ergonomia pode ser avaliado profundamente, monitorado e estimulado a melhoria continua das condições de trabalho. Porém mais que isso, promoverá a análise continuada dos indicadores e das justificativas dos casos de absenteísmo e rotatividade existente. Isso se dá através de um ciclo de análises contínuas das condições de trabalho, composta por grupos representativos da empresa.

Citado como um importante meio para fundamentação epidemiológica na empresa 
(Quadro 1 - etapa 11 / ver no Anexo A)) a sistemática adotada no Diagnóstico de Saúde e Estilo de Vida, criada pelo SESI (2012), é um meio para clarear a situação da empresa com relação aos índices de absenteísmo e presenteísmo, levando em conta os diversos outros fatores que exercem influência. Tem fundamentos epidemiológicos e se destina a traçar um panorama do local de trabalho, indicando a presença de doenças e fatores de risco que podem influenciar no absenteísmo, no presenteísmo e nos custos (de produção ou assistenciais). Neste diagnóstico de saúde e estilo de vida os seguintes fatores são analisados:

- Dados socioeconômicos, demográficos e culturais;

- Alimentação;

- Tabagismo;

- Consumo de bebidas alcoólicas;

- Morbidade referida;

- Utilização e acesso a serviços de saúde;

- Comportamento preventivo;

- Características do trabalho: horários, turnos, absenteísmo;

- Qualidade do sono;

- Desconforto osteomuscular;

- Presença de desconforto mental leve;

- Autoavaliação da saúde;

- Medidas de peso, altura, circunferência abdominal, pressão arterial e saúde bucal.

\section{2) Medidas de Controle (Quadro 1 - Etapa 2): (Ver no Anexo 1)}

Deve estar vinculado ao programa de ergonomia e aos demais programas relacionados à saúde, um programa de qualidade de vida, onde busca-se a melhoria e manutenção das condições de saúde individual, com programas de condicionamento físico, ginásticas preventivas específicas, programas de conscientização de limites e potencialidades individuais, conhecimento corporal, relaxamento, Programa de Incentivo Nutricional, Programa de Prevenção a Doenças Crônicas, dentre outros.

Quelhas, Zago e Penatti (2006) revelam que devem ser considerados para melhoria nos índices de absenteísmo a implantação do Comitê de Ergonomia: com um programa intenso de melhoria da ergonomia e ainda programas de capacitação ergonômica, a ginástica laboral.

Penatti, (2006) e Marques (2015), concordam que se torna fundamental que práticas de programas como ginástica laboral. Além disso, políticas preventivas, um sistema de produção que leve em conta a ergonomia, comitês, segurança do trabalho, programas motivacionais etc. sejam implantadas com afinco, uma vez que serão a partir delas, que muitas ausências, por motivo de doenças, serão evitadas.

Kurcgant et al. (2015) relatam que outras ações de impacto positivo adotadas pelas empresas dizem respeito às relações pessoais e profissionais com reuniões onde são destacados pontos de valorização profissional, a escuta e a ajuda na solução de problemas pessoais e os canais de comunicação abertos.

Para os autores Quelhas, Zago e Penatti, (2006), as medidas concretas que a empresa deve tomar são basicamente as seguintes:

- Medidas processuais, administrativas ou disciplinares;

- Medidas preventivas orientadas para o ambiente de trabalho físico e psicossocial;

- Medidas reintegrativas, orientadas para a reintegração e reabilitação no local de trabalho;

- Medidas preventivas orientadas para o indivíduo e o reforço da sua capacidade de trabalho.

Vale esclarecer, como dito por Dourado e Lima (2011), que um aspecto importante a ser considerado é que as causas do absenteísmo nem sempre estão no trabalhador, mas na empresa, enquanto organização e supervisão deficientes, através da repetitividade de tarefas, da desmotivação e desestímulo, das condições desfavoráveis de ambiente e de trabalho, da precária integração entre os empregados e a organização e dos impactos psicológicos de uma direção deficiente, que não visa uma política prevencionista e humanista.

Santana et al. (2016) relata que é preciso repensar a organização do trabalho, as estruturas e modelos gerenciais e organizacionais, investir em programas de promoção a saúde dos trabalhadores, em ambientes de trabalho saudáveis, em número de recursos humanos suficientes para a demanda de trabalho e, 
sobretudo, como base de qualquer ação, a valorização do trabalhador com jornada de trabalho e remuneração justa e digna.

Com relação às brechas deixadas pelos métodos não formalizados de gestão de horas trabalhadas e programação falha da produção como na empresa estudada, ressalta-se a importância do controle eficaz de horas inativas fora do ambiente de trabalho em decorrência de problemas na seleção de trabalhadores e divisão de tarefas, essa não é uma falha incomum, como também não é de difícil resolução já que existem vários softwares destinados a planejamento e organização da produção. A autonomia de gestores quanto a abonar faltas e permitir folgas, de acordo com a política empresarial, pode sim ser preservada, já que diante de um macro controle do absenteísmo e presenteísmo, estas ações de gestão não irão representar danos importantes, mas benefícios estratégicos maiores.

\section{Conclusão}

Foram demonstrados fortes indícios de que o presenteísmo tem presença importante e deve ser enfocado. Demonstrou-se ainda a relação do absenteísmo com o modo de gestão, com os problemas no planejamento e programação da produção e a forte influência dos agentes de riscos ergonômicos levando a maior parte dos afastamentos por adoecimento serem com distúrbios osteomusculares.

Está claro que programas de ergonomia corporativos são importantes para a produtividade, a qualidade e o suporte para o bem estar nas companhias. Porém, a maioria dos programas tem foco majoritário nas questões de segurança e saúde. Desta forma, muitos trabalhos necessitam ser conduzidos com intuito de atingir a integração da ergonomia com as políticas gerais de uma companhia.

Deve haver uma atenção bastante especial em questões organizacionais do trabalho, tais como: rodízio, horários de trabalho, treinamentos, formação, competências, dentre outros, além das questões de saúde e segurança. A abordagem então deve ser macroergonômica e participativa, ou seja, envolver todos os fatores influentes sobre o trabalhador e sua capacidade de produção e envolvê-lo diretamente no processo de controle. Por isso, a importância da fundamentação epidemiológica e do aprofundamento de questões de ordem organizacional baseadas na análise precisa da atividade.

Ressalta-se que a principal premissa para que o modelo funcione é de que a ergonomia deve se tornar um tema estratégico para a empresa. Para isso, as ações ergonômicas precisam estar inseridas no cenário estratégico e integradas a uma prática de gestão do absenteísmo e presenteísmo.

Acredita-se que o estudo de desenvolvimento do modelo de gestão da ergonomia com ações para mitigar perdas com absenteísmo e presenteísmo pode ser continuado, abordando outros aspectos e se aprofundando em outras variáveis, como avançar no entendimento das possíveis métricas que podem ser utilizadas para compreender o desempenho dos fatores ligados à ergonomia e formular novos estudos que aprofundem na investigação sobre o presenteísmo, suas causas e repercussões.

\section{Referências}

CALIL, ÂNGELA SILVEIRA GAGLIARDO; JERICÓ, MARLI DE CARVALHO; PERROCA, MÁRCIA GALAN. Gerenciamento de recursos humanos em enfermagem: estudo da interface idade absenteísmo. Revista Mineira de Enfermagem, Jun 2015, Volume 19 № 2 Páginas $79-85$.

DOURADO M. M.; LIMA T. P. Ergonomia e sua importância para os trabalhadores de unidades de Alimentação e nutrição. Ensaios e Ciência Ciências Biológicas, Agrárias e da Saúde, v. 15, n. 4, 2011.

KURCGANT, AT AL, 2015, Absenteísmo do pessoal de enfermagem: decisões e ações de enfermeiros gerentes* - Rev Esc Enferm USP 2015; 49(Esp2):35-41

INOUE, K. C.; MATSUDA, L. M.; SILVA, D. M. P. P.; UCHIMURA, T. T.; MATHIAS, T. A. F. Absenteísmo - doença da equipe de enfermagem em unidade de terapia intensiva. Rev. bras. Enfermagem, Brasília, v.61, n.2. Mar./Apr., 2008. 
MARQUES DO, PEREIRA MS, SOUZA ACS, VILA VSC, ALMEIDA CCOF, OLIVEIRA EC. Absenteeism illness of the nursing staff of a university hospital. Rev Bras Enferm. 2015;68(5):594-600. DOI: http://dx.doi.org/10.1590/0034-

7167.2015680516.

MARTINIANO, A.; FERREIRA, R.P.; SASSI, R.J. Aplicação da Mineração de Dados na Identificação de Empregados Absenteístas e Presenteístas de uma Empresa de Courier da Cidade de São Paulo. In: ENCONTRO MINEIRO DE ENGENHARIA DE PRODUÇÃO, 7, 2012, Itajubá, MG. Anais... Itajubá, MG: EMEPRO, 2012.

PÁEZ A. L., ABELLÁN B. R.. Implicaciones del Presentismo em la Productividad laboral del Área de la Salud. Revisión Bibliográfica. (c) 2015. Asociación Costarricense de Medicina Legal y Disciplinas Afines. Medicina Legal de Costa Rica Edición Virtual Vol. 32 (1), Marzo 2015. ISSN 1409-0015.

PENATTI, I.; ZAGO, J.S.; QUELHAS, O. Absenteísmo: As conseqüências na gestão de pessoas. In: SIMPÓSIO DE EXCELÊNCIA EM GESTÃO E TECNOLOGIA, 3.,2006. Anais. SEGet, 2006.

PENHA. A. A. Absenteísmo e Presenteísmo. http://worksafety.blogspot.com.br/2012/03/abse nteismo-e-presenteismo.html E-mail: alexsandro.penha@grupovillela.com.br.

SANTANA LL, SARQUIS LMM, BREV C, MIRANDA FMD, FELLI VEA. Absenteísmo por transtornos mentais em trabalhadores de saúde em um hospital no sul do Brasil. Rev Gaúcha Enferm. 2016 mar;37(1):e53485.

SILVA, D. M.P.P.da; MARZIALE, M.H.P. Absenteísmo de Trabalhadores d e Enfermagem em um Hospital Universitário. Net, Ribeirão Preto. Rev. Latino - Am. Enfermagem, v.8, n.5, p. 44-51, out. 2000. Disponível em: $<$ http://www.scielo.br/scielo.php?script=sci_artt ext\&pid=S0104-11692000000500007>. Acesso em: 11 jan. 2012a.

VILELA, Rodolfo Andrade de Gouveia; ALMEIDA, Ildeberto Muniz de; MENDES, Renata Wey Berti. Da vigilância para prevenção de acidentes de trabalho: contribuição da ergonomia da atividade. Ciênc. saúde coletiva, v.17, n.10, p. 2817-2830, 2012.

YIN. K. R. Estudo de Caso Planejamento e Métodos. Porto Alegre: Bookman, 2005 


\section{Anexos e Apêndices}

\section{ANEXO A:}

Quadro 1(a) - Ações ergonômicas para mitigar perdas com absenteísmo e presenteísmo

\begin{tabular}{|c|c|c|c|}
\hline \multicolumn{4}{|c|}{ ETAPA 1 - INVESTIGAÇÄO } \\
\hline PROPOSTA & SITUAÇÃO ATUAL & $\begin{array}{l}\text { LITERATURA } \\
\text { CIENTIFICA }\end{array}$ & MEDIDAS DE CONTROLE \\
\hline $\begin{array}{l}\text { Mapeamento } \\
\text { Eficaz e Periódico } \\
\text { do Presenteismo }\end{array}$ & $\begin{array}{l}\text { Uso exclusivo do indice de } \\
\text { absenteismo e direcionamento } \\
\text { de medidas excessivas à } \\
\text { redução do absenteismo. } \\
\text { Além disso, há fortes indicios } \\
\text { de trabalhadores que } \\
\text { permaneceram no trabalho, sem } \\
\text { ao menos procurar o serviço } \\
\text { médico, apesar do adoecimento. }\end{array}$ & $\begin{array}{l}\text { Call, et al, (2015), } \\
\text { Martiniano (2012) e } \\
\text { Martinez et al. (2007). }\end{array}$ & $\begin{array}{l}\text { Uso de instrumentos com } \\
\text { Stanford Presenteismo Scale-6 } \\
\text { (SPS-6) para avaliação do } \\
\text { presenteismo. }\end{array}$ \\
\hline $\begin{array}{l}\text { Fundamentação } \\
\text { Epidemiológica } \\
\text { Adequada da } \\
\text { População } \\
\text { Trabalhadora }\end{array}$ & $\begin{array}{l}\text { Ausència de fundamentos } \\
\text { epidemiológicos } \\
\text { contextualizados que se } \\
\text { destinam a traçar um panorama } \\
\text { do local de trabalho, indicando a } \\
\text { presença de doenças e fatores } \\
\text { de risco que podem influenciar } \\
\text { no absenteismo/presenteismo. }\end{array}$ & $\begin{array}{l}\text { Sistemática adotada no } \\
\text { Diagnóstico de Saúde } \\
\text { e Estilo de Vida, criada } \\
\text { pelo SESI (2012) }\end{array}$ & $\begin{array}{l}\text { Traçar um panorama do } \\
\text { local de trabalho, indicando a } \\
\text { presença de doenças e fatores } \\
\text { de risco que podem influenciar } \\
\text { no absenteismo/presenteismo. }\end{array}$ \\
\hline $\begin{array}{l}\text { Uso da } \\
\text { Ergonomia para } \\
\text { Aprofundamento } \\
\text { das Informaçöes. }\end{array}$ & $\begin{array}{l}\text { Desconexão entre os achados } \\
\text { da AET e os indices de } \\
\text { absenteismo/presenteismo. } \\
\text { Utilização frágil dos conceitos } \\
\text { ergonómicos no combate aos } \\
\text { custos altos do absenteismol } \\
\text { presenteismo. }\end{array}$ & $\begin{array}{l}\text { Vilela et al. (2011) } \\
\text { e Inoue et al. (2008) } \\
\text { Quelhas, Zago e } \\
\text { Penatti, 2006. }\end{array}$ & $\begin{array}{l}\text { Análise periódica da } \\
\text { atividade através do uso de }\end{array}$ \\
\hline $\begin{array}{l}\text { Investigação } \\
\text { sobre os picos } \\
\text { de ocorrèncias } \\
\text { sazonais para } \\
\text { aprofundamento } \\
\text { das informaçöes. }\end{array}$ & $\begin{array}{l}\text { Ocorreram picos de } \\
\text { apresentaçäo de atestados } \\
\text { vinculados ao CID M, nos meses } \\
\text { de março e abril do ano de 2014, } \\
2015 \text {. }\end{array}$ & $\begin{array}{l}\text { Cali, ef al, (2015), } \\
\text { Martiniano (2012) e } \\
\text { Martinez et al. (2007). }\end{array}$ & $\begin{array}{l}\text { compreender melhor as causas } \\
\text { organizacionais. }\end{array}$ \\
\hline
\end{tabular}

Fonte: Autora (2016) 
Quadro 1(b) - Ações ergonômicas para mitigar perdas com absenteísmo e presenteísmo

\begin{tabular}{|c|c|c|c|}
\hline \multicolumn{4}{|c|}{ ETAPA 2 - MEDIDAa DE CONTROLE } \\
\hline PROPOSTA & IITUAÇAO ATUAL & $\begin{array}{l}\text { UTERATURA } \\
\text { CIENTIFICA }\end{array}$ & MEDIDAS DE CONTROLE \\
\hline \multirow{2}{*}{$\begin{array}{l}\text { Implartaçâo } \\
\text { das Medidas } \\
\text { de Controle } \\
\text { S.geridas pela } \\
\text { Eggono-nia. }\end{array}$} & \multirow{2}{*}{ 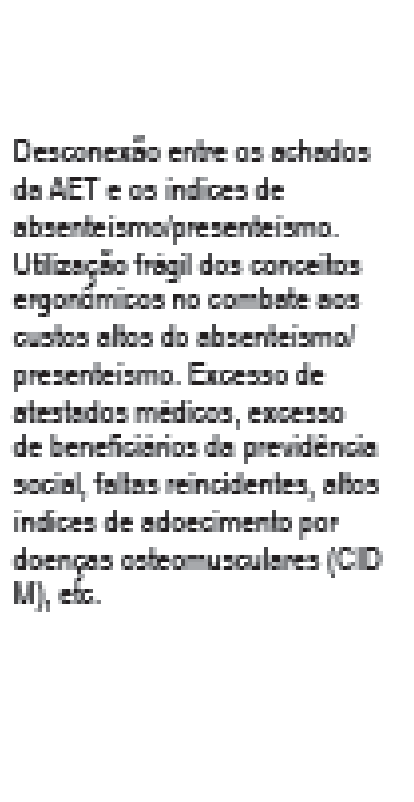 } & $\begin{array}{l}\text { Cail, ef al, (2015) } \\
\text { Meríniano (2012) e } \\
\text { Merínez et al (2007). } \\
\text { Quehas, Zago e } \\
\text { Penath, (2006). }\end{array}$ & 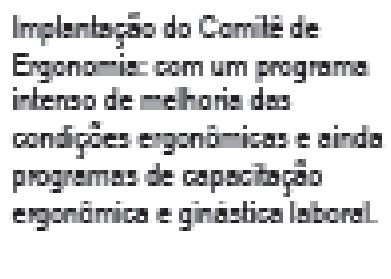 \\
\hline & & $\begin{array}{l}\text { Penath, (2006), e } \\
\text { Marques, (2015) } \\
\text { e Kurcgant, ef al, } \\
\text { (2015). }\end{array}$ & 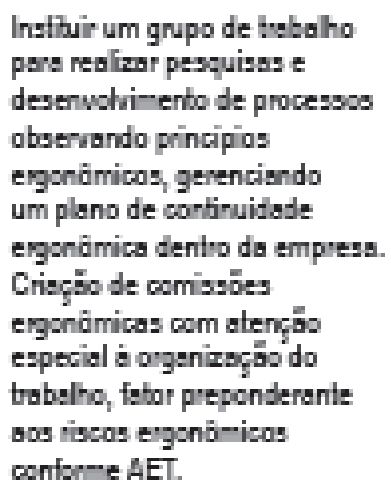 \\
\hline \multirow{2}{*}{$\begin{array}{l}\text { Atenção a } \\
\text { Orgenizeçäs } \\
\text { do Trabaho. } \\
\text { Mehoria na } \\
\text { Integração Entre } \\
\text { os Empregedose } \\
\text { a Onganização. }\end{array}$} & \multirow{2}{*}{ 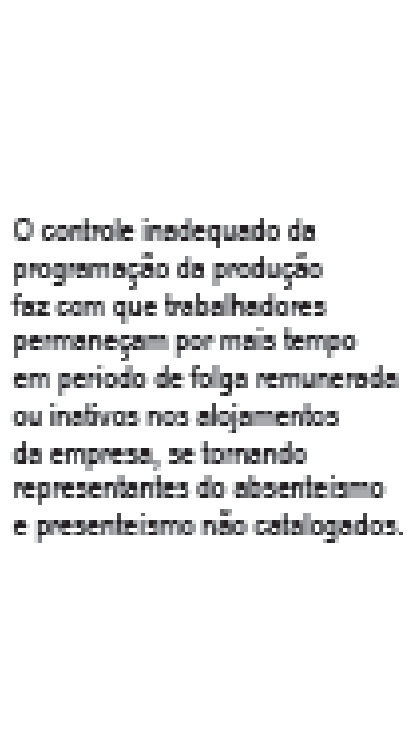 } & $\begin{array}{l}\text { Quelhas, Zago e } \\
\text { Penstt (2005). }\end{array}$ & $\begin{array}{l}\text { Medidas processuais, } \\
\text { administrafivas ou disciplinares, } \\
\text { medidas preverbivas orientedas } \\
\text { para o individuo, medidas } \\
\text { preventivas orientedas pars } \\
\text { o ambierbe de trabalho fisico } \\
\text { e psicossocial e medidas } \\
\text { reintegrativas. }\end{array}$ \\
\hline & & $\begin{array}{l}\text { Dourado e Lima } \\
\text { (2011), Que has, Zago } \\
\text { e Penat5, (2006), } \\
\text { Santana, et al, (2016]. }\end{array}$ & 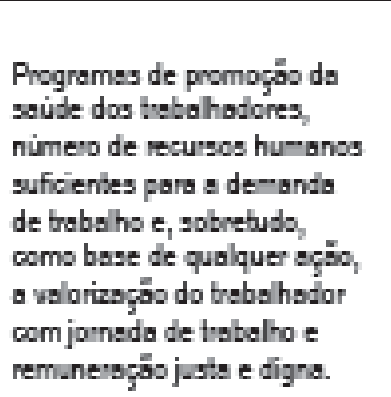 \\
\hline
\end{tabular}

Fonte: Autora (2016) 